\title{
VISITA ESTENDIDA NA UNIDADE DE TERAPIA INTENSIVA - RELATO DE EXPERIÊNCIA
}

\author{
ARTIGO ORIGINAL \\ OLIVEIRA, Marilena Gomes ${ }^{1}$ \\ BRASILEIRO, Marislei ${ }^{2}$
}

OLIVEIRA, Marilena Gomes. BRASILEIRO, Marislei. Visita Estendida na Unidade de Terapia Intensiva - Relato de Experiência. Revista Científica Multidisciplinar Núcleo do Conhecimento. Ano 04, Ed. 08, Vol. 06, pp. 184-194. Agosto de 2019. ISSN: 2448-0959

\section{RESUMO}

Objetivo: descrever a experiência de um projeto de visita estendida implantado em uma Unidade de Terapia Intensiva (UTI) em um hospital público de grande porte na cidade de Uberlândia-MG. Trata-se de um relato de experiência com abordagem crítico reflexivo de cunho descritivo-compreensivo vivenciado pela autora durante três meses de observação na unidade. O estudo possibilitou identificar a importância de manter um acompanhante na UTI além do tempo restrito de visita, observar e analisar fatores positivos e negativos desta iniciativa e a importância de se humanizar o ambiente. Percebe-se que a intenção do projeto é válida, colabora no processo de recuperação do paciente, ou da redução do agravo que o levou a internação, promove a humanização na assistência através do acolhimento e faz com que o acompanhante se torne participante efetivo do processo de internação do paciente.

Palavras Chaves: UTI, humanização, visita.

\footnotetext{
${ }_{1}^{1}$ Pós - Graduanda em UTI; Graduada em Enfermagem-Licenciatura e Bacharelado.

2 Doutora em Ciências da Saúde.
} 


\section{INTRODUÇÃO}

As Unidades de Terapia Intensiva - UTI surgiram a partir da necessidade de aperfeiçoamento e concentração de recursos materiais e humanos para o atendimento à pacientes graves, em estado crítico, mas tidos ainda como recuperáveis, a partir da assistência multidisciplinar contínua, por profissionais especializados, centraliza-os em um mesmo espaço físico, porém separados através de divisórias garantindo assim a integridade física, moral e social. ${ }^{1}$

O ambiente e a rotina da UTI exigem do profissional atuante, atenção e dedicação integral ao paciente e a monitorização contínua do mesmo assim como na evolução do quadro clínico, o que pode influenciar na oferta de uma assistência humanizada, através do acolhimento, da escuta, da companhia seja do paciente ou do familiar.

A admissão de u. paciente na UTI atinge não só o paciente em si, mas a sua família e dos que convivem na sua rotina. Mudança nas rotinas, nos sentimentos, nas expectativas são observados nos familiares e acompanhantes que permanecem junto ao paciente durante sua internação.

A internação em uma unidade de tratamento intensivo é um evento que gera estresse, tanto no paciente quanto nos seus familiares, despertando sentimentos como angústia, medo e sofrimento. ${ }^{2}$

Inserem - se neste contexto os familiares dos pacientes criticamente enfermos, que, além da tensão de possuir um ente querido hospitalizado, vivenciam incertezas a respeito da evolução e prognóstico e aguda, e essa situação pode gerar desorganização, desamparo e estresse à família. ${ }^{3}$

Diante deste contexto, humanizar o ambiente torna-se uma maneira eficaz de transformar a realidade da internação tanto para o paciente quanto para o familiar para um momento menos estressante estreitando as relações estabelecidas no setor entre profissionais, pacientes e familiares. 
Ter um familiar internado em UTI costuma ser motivo de mais estresse e ansiedade, uma vez que, normalmente, a presença dos familiares é permitida por curtos períodos e os pacientes ficam, integralmente, sob os cuidados da equipe de saúde. Diante disso, é indispensável que o profissional da enfermagem acolha a família do paciente internado nesses setores, atentando para seus medos e angústias, no intuito de minimizá-los por meio de um cuidado humanizado. ${ }^{4}$

Em 2004 foi criada no Brasil a Política Nacional de Humanização (PNH) uma versão aprimorada do Programa Nacional de de humanização da Assistência Hospitalar criada em 2001, que propõe a ampliação do acesso dos visitantes nas unidades de internação e cita que o um membro familiar presente no contexto da internação é importante não só para acompanhar mas para ser orientado como cuidador leigo daquele que é assistido pela unidade de saúde. A visita aberta é uma proposta da $\mathrm{PNH}$ que tem como objetivo ampliar o acesso dos visitantes às unidades de internação garantindo o elo entre o paciente, sua rede social e os serviços de saúde. ${ }^{5}$

O cuidado humanizado nessa vertente envolve o estabelecimento de um elo de acolhimento e envolvimento entre a equipe, o familiar e o paciente visando a reabilitação e permanência do paciente na UTI por tempo menor do que o esperado.

Percebe-se, portanto, que a humanização em UTI perpassa por um cuidado livre de juízos de valor e alcança um elo com a família a ponto de estabelecer uma relação terapêutica que favoreça a reabilitação do doente. Para tal, o momento da visita de parentes na UTI deve ser bem construído e bem vivido, o que poucas vezes acontece. 6

\section{OBJETIVO}

O estudo objetiva descrever a experiência vivenciada e observada pela autora da presença da visita permanente em UTI, a partir da iniciativa lançada em um hospital da cidade de Uberlândia-MG, intitulada visita estendida, e a partir desta refletir sobre as relações interpessoais, humanização, acolhimento e fatores positivos e negativos desta iniciativa. 


\section{METODOLOGIA}

Trata-se de um estudo descritivo e observacional, na modalidade de relato de experiência. Ocorreu a partir da vivência da pesquisadora com uma equipe multidisciplinar de um hospital na cidade de Uberlândia-MG durante a vigência do projeto de visita estendida implantando para os familiares internados na UTI desde hospital.

O relato de experiência é um tipo de informação que consiste em registrar situações e/ou casos relevantes que ocorreram durante determinada situação. Trata-se de um estudo tipo relato de experiência, de delineamento descritivo observacional. Ocorreu a partir da vivência da pesquisadora durante a atuação profissional como técnica em enfermagem em uma unidade de terapia intensiva que implantou a visita estendida na UTI como parte do projeto de humanização institucional, que abrangeu analise da postura da equipe multiprofissional da UTI e dos acompanhantes nos leitos da UTI. Foram utilizados para o referencial teórico, artigos científicos, através de endereços eletrônicos como SCIELO e LILACS.

\section{RELATO DA EXPERIÊNCIA E DISCUSSÃO}

\subsection{DESCRIÇÃO DA UNIDADE E COMO FUNCIONAVA A VISITA} FAMILIAR

A vivência ocorreu no setor de Terapia Intensiva de um hospital, localizado na cidade de Uberlândia, durante a prática profissional da autora como técnica em enfermagem. A unidade é composta por 40 leitos, divididos em 4 unidades de 10 leitos cada.

Inicialmente a visita na unidade acontecia somente nos horários pré determinados no período matutino e vespertino sendo limitada a 2 visitas por horário, por leito. Tendo em vista a necessidade de acolhimento e humanização junto aos familiares e a expectativa de que manter um acompanhante em tempo maior beira leito do paciente favorece o processo de recuperação do paciente, o hospital juntamente com a equipe diretora da UTI lançou a iniciativa da Visita Estendida na UTI. 


\subsection{A VISITA ESTENDIDA NA UTI}

Esta nova proposta permite a permanência de um acompanhante beira leito exceto no caso de pacientes em estado grave, no período de $12 \mathrm{~h}$ compreendido entre $09 \mathrm{~h}$ da manhã e $21 \mathrm{~h}$, sendo que podem se cadastrar para visita estendida somente 02 acompanhantes que receberão treinamento para permanecer na UTI e para posteriores revezamentos caso seja necessário.

A possibilidade de flexibilidade no horário e de número de visitantes da UTI também aparece como uma boa estratégia de acolhimento, porque os familiares se sentem amparados, ajudados, compreendidos e confortados. Assim, pelo menos parte das suas necessidades afetadas é atendida com esta estratégia, sendo que, neste momento de muita angústia e de muita ansiedade, estes minutos a mais ao lado do seu ente querido representam respeito aos vínculos afetivos. ${ }^{7}$

Espera-se ser acolhido ao adentrar em um serviço tão complexo como a UTI, pois é a partir do tratamento respeitoso e saudoso que se iniciam e estreitam laços importantes em situações estressoras da vida nas quais mesmo um simples local de espera pode tornar-se acolhedor. ${ }^{8}$

No decorrer da inciativa foram observados alguns pontos a melhorar que foram se otimizando com o passar do dias. Os acompanhantes tomados pelo sentimento de responsabilidade e pela emoção da autorização de sua permanência algumas vezes deixavam de seguir as regras institucionais administrativas e assistenciais. A lavagem das mãos ao adentrar ao recinto algumas vezes deixava de acontecer, os cuidados com as precauções padrão de isolamento, os cuidados com a prestação de cuidados ao paciente, e com os equipamentos tecnológicos do local. Diante essa realidade, iniciaram-se os treinamentos para os acompanhantes oferecidos pelos enfermeiros da unidade afim de prepará-los para permanecer no local sem causar danos e prejuízos principalmente ao paciente.

O enfermeiro desenvolve papel fundamental no momento de informar e acolher os familiares para que entendam a dinâmica da unidade. Cabe a esse profissional dar 
suporte e reconhecer os familiares como indivíduos que também sofrem e precisam de cuidados para então ser adjuvante na assistência ao paciente, buscando identificar tais necessidades na intenção de implementar o planejamento de intervenções que atendam às necessidades tanto do paciente quanto da família. ${ }^{2}$

O enfermeiro além de ser líder, capacitar a equipe e sistematizar a assistência de enfermagem, deve também realizar a educação em saúde. No entanto, apesar de ser algo previsto em lei, muitas vezes durante o cotidiano e o processo de trabalho, as orientações, acolhimento e a educação em saúde não são praticadas, incluindo a ambiência de terapia intensiva. ${ }^{9}$

O acompanhante enquanto visita estendida precisa ser bem acolhido principalmente pela equipe de enfermagem, pois todas as condutas serão acompanhadas e questionadas pelo acompanhante, o qual é muitas vezes é leigo no assunto e procura entender o que se faz com o paciente. Observou-se nesta vivência uma certa resistência por parte da equipe técnica, pelo motivo de os acompanhantes muitas vezes modificarem a rotina e o planejamento do profissional, não ter interesse na ajuda com o paciente e principalmente por ser um questionador atuante.

A UTI, por caracterizar-se como um ambiente de alta complexidade e densidade tecnológica, e que há inúmeras situações em que o paciente necessita de atendimento imediato, muitos profissionais entendem que a presença contínua da família junto ao leito do paciente pode dificultar a assistência a ser prestada, desencadeando estresse no paciente, afetando seu descanso e o processo de reabilitação. Além disso, a presença de determinados familiares pode causar aumento na carga de trabalho para os profissionais da unidade e ocasionar atrasos no cumprimento de tarefas e rotinas. 2

A equipe precisa considerar as necessidades da família diante de situações estressantes e estabelecer um plano de cuidados que seja construído e continuamente validado, avaliado e reavaliado. Desta forma, a interação da equipe de enfermagem com os familiares e o paciente será estabelecida através do diálogo e da busca dos significados que as experiências de doença geram em cada pessoa. ${ }^{6}$ 
Analisando a rotina diária desta UTI, em que maioria das escalas de trabalho estavam reduzidas devido a falta de funcionários (baixa adesão de convocados), a presença do acompanhante como visita estendida para alguns era uma estratégia em que proporcionava ao profissional a oportunidade de agregar a ajuda do acompanhante nas tarefas diárias do paciente, como auxilio no banho, nas trocas de fraldas, na oferta de dieta, de água, na mudança de decúbito dentre outras tarefas de simples realização. Percebe-se que para que esta conduta obtivesse sucesso o acompanhante precisava ser bem acolhido na rotina, bem educado quanto às tarefas e quanto à vontade própria de ser útil naquele momento. Observou-se que a presença do acompanhante gerava segurança no paciente durante a realização destas tarefas, inclusive na de deambular ou sedestar quando possível. O próprio acompanhante era incentivador do paciente na realização de tarefas para favorecer o bem estar, apoiando a equipe de enfermagem.

A internação em UTI repercute diretamente nas famílias dos doentes, sendo assim, o cuidado da equipe multiprofissional não pode estar focado apenas no paciente, mas precisa ampliar-se para toda a sua rede. Situações estressoras, quando bem acolhidas, podem ser favorecedoras de promoção de desenvolvimento. Quando os profissionais reconhecem e compreendem as necessidades e os sentimentos dos familiares e sujeitos internados, conseguem realizar uma assistência mais qualificada e humanizada, promovendo as bases para que o efeito estressor da hospitalização seja melhor absorvido emocionalmente pelo paciente e sua família. ${ }^{10}$

Em casos de pacientes sedados ou em períodos de confusão mental, percebeu-se um despreparo do acompanhante para tal realidade, onde mais uma vez tornou-se necessário o treinamento para todos. Outra realidade que necessitou intervenção foi de perceber que os acompanhantes eram disseminadores de informações sigilosas do ambiente da UTI afetando familiares de outros pacientes ou até mesmo condutas profissionais.

A rotina imposta ao paciente pode ser amenizada evitando-se a separação do convívio familiar por meio das visitas diárias e da interação família-paciente com a equipe, apoiando e participando do cuidar. Para que essa assistência seja eficaz, é 
importante, sendo necessário, que a equipe passe informações diárias, com palavras claras condizentes, respeitando o nível sociocultural dos familiares ${ }^{11}$

A inclusão e o saber do familiar no cuidar do seu ente viabilizam um processo de transformação, pois em acompanhar o tratamento, receber orientações e treinamento. Desta forma o acompanhante pode participar ativamente de ações de apoio à recuperação do cliente, seja no domicilio ou hospital, ou seja, o familiar passa a ser uma parte integrante na reabilitação desse indivíduo doente..(Freitas ,2012 apud Silva,2014)

A equipe precisa considerar as necessidades da família diante de situações estressantes e estabelecer um plano de cuidados que seja construído e continuamente validado, avaliado e reavaliado. Desta forma, a interação da equipe de enfermagem com os familiares e o paciente será estabelecida através do diálogo e da busca dos significados que as experiências de doença geram em cada pessoa. ${ }^{6}$

Uma inovação importante foi a elaboração e implantação de uma cartilha explicativa para os familiares entenderem seu papel durante a visita estendida na UTI.

\section{CONSIDERAÇÕES FINAIS}

A humanização tem sido um assunto muito discutido, porém muitas instituições ainda são resistentes em colocar em prática visto a mudança de rotina institucional e adaptação da equipe. Existem muitos estudos teóricos e políticas para embasar a garantia dos direitos dos usuários do sistema de saúde estimulando a implantação para melhor assistência ao paciente e seu acompanhante.

Com a teoria do assunto, acredita - se que na realidade implantar a humanização seja fator essencial para aprimorar a assistência a saúde, centrando nas necessidades do paciente e da família. Para isso a atuação de uma equipe multidisciplinar efetiva proporciona acolhimento, favorece o diálogo profissional com o familiar e permite a percepção do familiar frente a situação atual do paciente, diminuindo ansiedades e perspectivas em relação a internação. 
A vivência permitiu observar que o projeto é de grande valia e requer interação e comprometimento de todas as partes envolvidas, principalmente dos que estão na assistência direta ao paciente que são os mais resistentes devido a interferência do acompanhante nas rotinas do serviço.

Observaram-se na implantação do projeto, que são muitas dificuldades enfrentadas de ambas as partes, mas que com o tempo e as experiências vivenciadas o projeto vai tomando uma forma e atendendo os objetivos específicos de seu contexto. No decorrer das visitas estendidas na UTI, foi visível que a proposta favorece e contribui para melhora de alguns quadros clínicos específicos da internação em UTI, e a satisfação de algumas famílias em serem acolhidas no ambiente como participantes do cuidado e recuperação. Ressalta-se a necessidade de melhoria na comunicação entre a equipe multidisciplinar e a imposição de normas e regras do setor e esclarecimento das mesmas aos familiares.

Com esta proposta os aspectos preconizados pela Política Nacional de Humanização são garantidos e a equipe desempenha um cuidado holístico ao paciente e seu familiar.

\section{REFERÊNCIAS}

1. SILVA, Edlayne Francisca Almeida; COSTA, Mércia Mota da; SILVA, Valéria da Costa. A humanização da equipe de enfermagem em unidades de terapia intensiva adulta. TCC (Graduação) - Curso de Bacharel Enfermagem, Faculdade Integrada de Pernambuco, Recife Pe, 2013.

2. EUGÊNIO, Cláudia Severgnini; BECK FILHO, Marco Colomé; SOUZA, Emiliane Nogueira de. Visita aberta em uti adulto: utopia ou realidade. Revista de Enfermagem da UFSM, Rio Grande do Sul, Trimestral; 2017:539-549,

3. OLIVEIRA SS, MOREIRA NS, SANTOS NAS, LIMA JS, XAVIER ASG, SILVA SSB. Acolhimento aos familiares de pessoas hospitalizadas em unidades públicas de terapia intensiva da Bahia. CiêncCuid Saúde. 2016 jan /mar;15(1):93-100 
4. CAMPONOGARA, Silviamar et al. Percepções e necessidades de familiares de pacientes internados em unidade de terapia intensiva. Journal Of Research Fundamental Care On Line. Rio de Janeiro, 2013; 622-634.

5. BRASIL. MINISTÉRIO DA SAÚDE. HUMANIZASUS: POLÍTICA NACIONAL DE HUMANIZAÇÃO: A HUMANIZAÇÃO COMO EIXO NORTEADOR DAS PRÁTICAS DE ATENÇÃO E GESTÃO EM TODAS AS INSTÂNCIAS DO SUS. Brasília: Ministério da Saúde; 2004.

6. FÉLIX, Tamires Alexandre et al. Prática da humanização na visita em unidade de terapia intensiva. Revista Enfermagem Contemporânea, Ceará, 2014; v. 2, n. 3, p.143-153.

7. MAESTRI, Eleine et al. Avaliação das estratégias de acolhimento na Unidade de Terapia Intensiva. Revista da Escola de Enfermagem USP, São Paulo, 2012;46(1):75-81

8. LUIZ FF, CAREGNATO RCA, COSTA MR. Humanização na Terapia Intensiva: percepção do familiar e do profissional de saúde. Rev Bras Enferm [Internet]. [Edição Temática: Boas Práticas E Fundamentos Do Trabalho De Enfermagem Na Construção De Uma Sociedade Democrática]. 2017;70(5):1040-7.

9. SANTOS, Elizângela Santana dos et al. Acolhimento e Processo Educativo em Saúde a Familiares de Pacientes Internados em UTI Adulto. Cienc Cuid Saude, 2016,Out/Dez;15(4):639-646.

10. CABRAL,C.R.L; MACEDO,G.L;OJEDA,O.M;CARMEM,L. As Repercussões do processo de internação em UTI Adulto na Perspectiva de Familiares .Temas em Psicologia.Sociedade Brasileira de Psicologia,Ribeirão Preto SP,2016; vol.24,num.3:815-823.

11. SILVA,Janelara Bastos de Almeida. Familiar/acompanhante na Unidade de Tratamento Intensivo(UTI):interação com equipe de enfermagem. Dissertação (Mestrado)- Universidade Católica de Salvador.Superintendência de Pesquisa e Pós Graduação. Mestrado em Família na Sociedade Contemporânea Salvador,2014

Enviado: Julho, 2019. 
Aprovado: Agosto, 2019. 